\title{
Are researchers paying too much for attending dental meetings?
}

\author{
Clovis M. Faggion Jr*1 and Nikolaos N. Giannakopoulos ${ }^{2}$
}

\section{Key points}

Discusses the high fees for participants presenting research findings in dental meetings.
Suggests that presenters of research findings should pay lower fees than attendees.
Reports some suggestions to reduce the economic burden of participants presenting research findings in dental meetings.

\begin{abstract}
Dental meetings are important venues for sharing knowledge and experiences among researchers and clinicians. The costs for participating in such events, however, are high and have increased over the years. This opinion paper discusses the fairness of such a policy, with high costs for researchers presenting their findings, as well as some suggestions to reduce the economic burden of participants actively involved in presenting their research findings.
\end{abstract}

\section{Introduction}

Scientific conferences in several fields have three main dimensions of motivation: selfenhancement (for example, networking, education, and enhancement of one's career/ leadership/self-esteem); business/conference activities (business association-related activities and conference programmes); and sightseeing (outdoor recreation, travelling to desirable places, change of pace, and deals on conference packages). ${ }^{1}$ Researchers and clinicians frequently attend dental meetings to stay updated on new procedures and techniques, to present their research findings or clinical skills, and to connect with the professional community. Conference attendees also network with colleagues and associate with different interest groups within the dental community. Moreover, the information gathered at a dental meeting could be applied

'Department of Periodontology and Operative Dentistry, University of Münster, Münster, Germany; ${ }^{2}$ Department of Prosthodontics, University of Würzburg, Würzburg, Germany

${ }^{*}$ Correspondence to: Clovis Mariano Faggion Jr

EMail: clovisfaggion@yahoo.com

Refereed Paper.

Accepted 5 April 2019

DOI: 10.1038/s41415-019-0421-5 to the treatment of patients in order to improve the quality of dental health care provided.

There are different types of dental meetings in terms of their focus and the motivation. Some meetings are more focused on clinical practice than on research, although most of them try to maintain a research component in their programmes. Others set the focus mainly on the social component of the meeting, with the clinical- or research-orientated programmes functioning as a filler between the meeting's social or sightseeing opportunities. Dental meetings can also involve specialties, such as meetings of the International Association of Dental Research (IADR) and the World Dental Federation (FDI) World Dental Congress. Other meetings, such as the EuroPerio from the European Federation of Periodontology (EFP) or the meeting of the American Association of Orthodontists (AAO), involve more specific specialties. The exhibition aspect is common for all meetings, as exhibitors contribute to a conference significantly by renting exhibition booths and, of course, by acting as sponsors. Major general dental meetings such as the IADR and the FDI World Dental Congress are usually held annually, while others, such as EuroPerio, are held every three years. Aside from the invited and paid speakers, who are often the minority of the conference participants, the core of most meetings is the presentation of posters and oral lectures from researchers who pay regular fees to attend the meeting. Networking opportunities and costs appear to be significant predictors of the intention to attend a conference, ${ }^{2}$ and costs may be a major inhibitor for attending a congress. ${ }^{1,3}$ Hence, in the present opinion paper, we would like to point out researchers' and clinicians' perspectives regarding the financial costs of participation in dental congresses.

\section{Are dental meeting fees too expensive for researchers?}

As a basis for discussion, we will approach this question by examining the regular fees for nonmembers of the above-mentioned congresses. Participants in the IADR general session meeting 2019 paid US\$1,060 (non-IADR members, onsite registration). ${ }^{4} \mathrm{~A}$ student nonmember paid US $\$ 530$. In 2009, a student paid US\$265 for the same meeting, a difference of almost $100 \%$ in comparison to 2019. Regarding the FDI's World Dental Congress that will be held on 4-8 September 2019, international non-member dentists will be paying US $\$ 550$ onsite, US\$50 more than the fee in 2017 (that is, US $\$ 400$ for students or participants from countries classified according to the United 
Nations list of least developed countries). ${ }^{5}$ The situation is similar for speciality meetings. For example, to attend four days of EuroPerio9 (held on 20-23 June 2018), EFP non-members paid €930. ${ }^{6}$ Attending other speciality congresses such as the 2019 AAO annual session will cost US $\$ 2,150$ for non-members, including orthodontists, dentists and other dental specialists. ${ }^{7}$ Most organisers do not reveal the extent of the contribution of the congress sponsors, but the presence of dozens of sponsors in major congresses is a reality. For example, the IADR 2018 and EuroPerio 2018 meetings had 29 and 27 official sponsors, respectively. ${ }^{8,9}$

\section{Presentation of research findings}

Dental meetings that have a research component usually allow participants to submit abstracts of their own research to communicate these results to the dental community. This communication can occur in the form of a poster or very short oral presentations about the conducted research. ${ }^{10,11}$ Some congress organisers also allow for symposium proposals that, in the example of the IADR, typically take ' 90 minutes... unless approved otherwise. ${ }^{12}$ Other options, such as the FDI's new and emerging speaker series, offer up-and-coming professional educators the chance to present a one-hour lecture at the annual meeting. ${ }^{13}$ Finally, there are satellite symposiums that usually occur a few days before the main session. ${ }^{14}$ Most meetings strive to offer some awards for outstanding projects or presentations; ${ }^{10}$ however, these awards are limited as they are usually sponsored by third parties and require special registration and additional material. Some dental congresses offer travel grants, mainly for researchers travelling from underdeveloped countries, as well as reduced fees for participants from those countries. $^{4,5}$

\section{Burdens on research}

In order to produce valuable information from research, researchers invest lots of time and money. Researchers are regularly underpaid for this performance when compared to the payment possibilities for the same amount of time spent working in a dental office. In our opinion, this seems to be a 'reversal of values', where the agent that produces the core work (that is, the research output) still needs to pay as much to present it as the conference attendants do to hear about it. This would be similar to a Hollywood actor getting a role in a movie, after surviving hard competition, who still had to pay for participating in the film. One could assume that without the hard work of all the dental conference presenters, the meetings per se would not exist.

Hearing new research in one's field is a major motive for conference attendance ${ }^{3}$ and, according to the dental meeting organisers' estimations, ${ }^{15}$ around $70 \%$ of congress participants have an academic background. This percentage might be even higher at more research-orientated meetings, such as those of the IADR. Moreover, regarding congress events themselves, the presenting researchers are the ones who attend most of the congress programme due to the obligation of presenting or because of their own special interest in ongoing research. Other non-presenting participants may be more prone to enjoying sightseeing or a nice breakfast instead of attending the congress, especially at particular times; it is a common observation that early morning or Saturday afternoon sessions are generally poorly attended.

One could argue that researchers should include the expenses for a meeting in their budget for conducting a research project. However, funding through grants is generally limited and competitive, ${ }^{16}$ which makes the coverage of these fees unrealistic for most researchers. One could also argue that the author's affiliated department could cover these fees. Again, departmental budgets for covering dental meeting expenses are becoming scarce, and dental meetings must be selected in a strict manner. With the rise of open access publications, ${ }^{17}$ a part of this departmental budget is allocated to covering the required publication fees. Moreover, department fees are needed for supporting young researchers at the beginning of their careers as an incentive for continuing their research. Thus, not many extra economic resources are available for independent academic researchers attending dental meetings. Finally, some researchers are not affiliated with any university and need to pay for the meeting fees out of his or her own pocket.

\section{Questions to be answered}

The main question for discussion in this opinion article is why a researcher presenting research results, in the form of posters or oral lectures, needs to pay the same fees as a participant who only attends the meeting as a conference attendee. Another question that can also be raised: is the sponsorship from different companies, foundations or institutes enough to cover a substantial part of the fees for abstract presenters? For example, the IADR provides a great number of sponsorship opportunities, ${ }^{18}$ as the FDI does for companies, ${ }^{19}$ that presumably generate a substantial reward to support the logistics for planning and organising such a big event. Added to this revenue are the fees exhibitors must pay for booths or other advertisements when exposing their products. ${ }^{20}$ In addition, a greater number of meeting participants increases the final revenue of these companies and this could result in lower fees.

It is important to mention, however, that it is not easy to predict the number of participants for such congresses. For example, according to the FDI reports on the World Dental Congress, there were around 19,437 participants in New Delhi in 2014, around 16,000 in Bangkok in 2015, around 11,730 in Poznań in 2016, and 8,000 in Madrid in 2017 and in Buenos Aires in 2018. The fluctuation in conference attendance depends on many unpredictable global and regional factors. Therefore, there is a high risk in managing such an international congress, especially due to the idea of holding the congress in different locations worldwide in order to serve political and/or touristic purposes. Both the number of participants and the congress cost may vary significantly. However, dental meeting organisers might try to anticipate the number of participants by having attendees and presenters RSVP to the conference.

Our concern is whether dental meetings would be feasible with less expensive fees, at least for the presenters who have already invested much time and money in conducting their research and presenting their findings. Clinicians and others interested in participating only as viewers (that is, without bringing new research findings) could still be charged the standard fees. This would be a fairer treatment for those who have made/make efforts for the development of our field. And ultimately, the efforts of all parties involved (for example, meeting organisers, researchers, clinicians and industry members) have more or less the same aim: to develop the field of dentistry as a whole and to improve the delivery of care to patients. In fact, without the attendance of active researchers presenting abstracts, the full scientific programme of the meetings would be poor or even non-existent. 


\section{Are dental meetings worth attending?}

Some criticism has been raised regarding the utility of medical conferences. ${ }^{21}$ In this article, ${ }^{21}$ the author reports the superficial peer review conducted to accept abstracts and the lack of full publication of these abstracts in peer-reviewed journals as weaknesses of such meetings. A study published in 2007 concluded that only $63 \%$ of the biomedical results from abstracts reporting randomised studies and controlled trials are published in full. ${ }^{22}$ This situation has not improved much over the years, as reported in the updates of this study. ${ }^{23}$ Worse, in dentistry, only $30 \%$ of the abstracts presented at dental conferences are published in full. ${ }^{24}$

There are also supporters of scientific meetings. For instance, some argue that such conferences are worth attending because of potential social contacts that could facilitate the scientific careers of students and young researchers. ${ }^{25}$ Another reason for attending such meetings is the possibility of busy clinicians to be (re)connected with new developments in the profession. ${ }^{26}$ Beyond these benefits of social interaction at conferences, we believe that some dental meetings are worth attending because of the feedback presenting participants might receive on their research. Through the interaction with so many people with different backgrounds presenting on a wide range of projects, participants might get good ideas for other projects.

Nevertheless, we ask whether it is worth investing huge fees in such meetings. To these fees, more logistic costs are applied (travel, hotel, meals, days out of office etc), which makes attending conferences a real economic challenge for most researchers. In light of the constrained financial support for congress attendance in the academic field, ${ }^{3}$ conference organisers should reconsider their policies as the cost of registration and the choice of destination and/or venue are to a certain extent (if not completely) under their control. Moreover, we should keep in mind that the number of dental meetings yearly is extremely high if we take into account the vast number of dental organisations around the world. Parallel congresses (for example, the
IADR global and IADR division meetings or the FDI and ADA meetings) lead to a lower number of attendants per congress, increasing the fees per attendant and forcing researchers to submit multiple abstracts on the same topic, lowering the scientific significance of these events. If the attendance costs were lowered, researchers would have the opportunity to participate in a greater number of meetings, increasing the opportunities to learn and improve as professionals.

We suggest that dental meetings could more intensively work towards providing lower logistic costs (for example, smaller fee rates for accommodation) for those presenting research findings. This could be achieved in the form of partnerships with hotels in the city where a meeting will be held (this happens already for most congresses but usually with the most expensive hotels). The same strategy could be implemented for flight tickets, where conference presenters could get discount prices from several airlines.

\section{Conclusion}

In conclusion, dental conferences should charge different fees for presenters and attendees. Lower fees for presenters would allow a greater number of participants to become actively involved in research and in presenting new research findings. This measure would also be, in our opinion, a fairer treatment for researchers.

\section{References}

1. Rittichainuwa B N, Beck J A, Lalopa J. Understanding Motivations, Inhibitors, and Facilitators of Association Members in Attending International Conferences. Journal of Convention \& Exhibition Management 2001; 3: 45-62.

2. Mair J, Thompson K. The UK association conference attendance decision-making process. Tourism Manage 2009; 30: 400-409.

3. Mair J, Lockstone-Binney L, Whitelaw P A. The motives and barriers of association conference attendance: Evidence from an Australasian tourism and hospitality academic conference. J Hosp Tour Res 2018; 34: 58-65.

4. International Association for Dental Research. Online information available at http://www.iadr.org/2019iags/ registration (accessed March 2019).

5. FDI World Dental Congress. Registration Pricing. 2019. Available at https://www.world-dental-congress.org/ registration/pricing (accessed May 2019)

6. European Federation of Periodontology. Programme: Registration. 2018. Available at https://www.efp.org/ europerio9/programme/registration.html (accessed May 2019)
7. American Association of Orthodontists. Registration Fees. 2019. Available at https://meetings.aaoinfo.org/ meetings/event-page/2019annualsession/registrationfees/ (accessed May 2019).

8. International Association for Dental Research. Online information available at https://iadr2018.zerista.com/ exhibitor/sponsor?conference_id=3889\&exhibitor_ order=sponsorship\&terms $=$ \&exhibitor_page $=($ accessed March 2019).

9. European Federation of Periodontology. Exhibitor Information. 2017. Available at https://www.efp.org/ europerio9/sponsors-and-exhibitors/exhibitor-info.html (accessed May 2019).

10. International Association for Dental Research. Online information available at https://www.iadr org/Portals/69/docs/Meetings//AGS/2019/19/A CallforAbstracts.pdf?ver=20180706-150: 731-957 (accessed March 2019).

11. FDI World Dental Congress. Poster abstract submission. 2019. Available at https://www.abstractscorecard.com/ cfp/submit/login.asp?EventKey=LJJMMLRC (accessed May 2019).

12. International Association for Dental Research. Online information available at http: //www.iadr. org/Portals/69/docs/Meetings/WCPD/17WCPD_ SymposiumProposalGuidelines.pdf (accessed March 2019).

13. FDI World Dental Congress. Do you have what it takes to speak at the ADA 2019? Available at https://www.conferenceabstracts.com/cfp2/login. asp?EventKey=BTBNQVRE (accessed May 2019).

14. International Association for Dental Research. Online information available at https: //www.iadr. org/Portals/69/docs/Meetings/IAGS/2019/19IA SessionProposal Guidelines.pdf (accessed March 2019).

15. FDI World Dental Congress. Sponsorship and Exhibition Prospectus. 2018. Available at http://2018. worlddentalcongress.org/panel/datas/genel/files/ exhibition___sponsorship_prospectus_new.pdf (accessed May 2019).

16. von Hippel T, von Hippel C. To apply or not to apply: a survey analysis of grant writing costs and benefits. PLOS One 2015; 10: e0118494.

17. Hua F, Shen C, Walsh T, Glenny A M, Worthington H. Open Access: Concepts, findings, and recommendations for stakeholders in dentistry. J Dent 2017; 64: 13-22.

18. International Association for Dental Research. Online information available at http: //www.iadr. org/2019iaSponsorship (accessed March 2019).

19. FDI World Dental Congress. Sponsorship and Exhibition Prospectus. 2019. Available at https://www. world-dental-congress.org/docs/librariesprovider173/ default-document-library/ada-fdi-2019-exhibitor-andsponsorship-prospectus.pdf?sfvrsn=0 (accessed May 2019).

20. International Association for Dental Research. Online information available at http: //www.iadr.org/portals/69/ docs/meetings/2018ep.pdf (accessed March 2019).

21. Ioannidis J P. Are medical conferences useful? And for whom? JAMA 2012; 307: 1257-1258.

22. Scherer R W, Langenberg $P$, von Elm E. Full publication of results initially presented in abstracts. Cochrane Database Syst Rev 2007: 2: MR000005.

23. Scherer R W, Meerpohl J J, Pfeifer N, Schmucker C, Schwarzer $\mathrm{G}$, von Elm E. Full publication of results initially presented in abstracts. Cochrane Database Syst Rev 2018; 11: MR000005.

24. Hua F, Walsh T, Glenny A M, Worthington $H$. Thirty percent of abstracts presented at dental conferences are published in full: a systematic review. I Clin Epidemiol 2016; 75: 16-28.

25. Cumberworth A, Cumberworth J, Sharp S. Usefulness of medical conferences. JAMA 2012; 308: 31-33.

26. Braun M. Usefulness of medical conferences. JAMA 2012; 308: 31-33. 